\title{
Características físicas de goiabas (Psidium guajava L.) submetidas a tratamento hidrotérmico
}

\author{
Stella M. J. Vieira ${ }^{1}$, Sandra M. Couto ${ }^{2}$, Paulo C. Corrêa ${ }^{2}$, Ana E. O. dos Santos ${ }^{3}$, Paulo R. Cecom ${ }^{4}$ \& Danilo J. P. da Silva ${ }^{5}$
}

\begin{abstract}
RESUMO
As perdas pós-colheita de frutas e hortaliças podem ser reduzidas se práticas adequadas desde a colheita até a sua comercialização forem adotadas, para tanto é necessário não só o conhecimento dos processos fisiológicos do produto, mas também uma infra-estrutura e logística de distribuição adequada. $\mathrm{O}$ uso indiscriminado de produtos químicos para erradicação de pragas e doenças na lavoura e no período pós-colheita está sendo substituído com sucesso por métodos que não causem danos ao homem nem ao meio ambiente, razão por que tratamentos físicos (aplicação de calor, frio ou radiação ionizante) estão sendo amplamente pesquisados. Foram avaliados, neste trabalho, alguns parâmetros relacionados à qualidade física e fisiológica de goiabas Pedro Sato, após a imersão de frutos íntegros em água a temperatura de $47{ }^{\circ} \mathrm{C}$, durante 6 min, e armazenadas a 8 e $22{ }^{\circ} \mathrm{C}$, com umidade relativa média igual a $89 \%$. Observou-se de maneira geral, que o tratamento hidrotérmico proposto, promoveu retardamento na perda de massa e na firmeza da polpa durante o período de armazenamento mas não se constatou ascensão climatérica na produção de $\mathrm{CO}_{2}$ e etileno.
\end{abstract}

Palavras-chave: pós-colheita, banho-maria, etileno

\section{Physical characteristics of guava (Psidium guajava L.) submitted to hot water treatment}

\begin{abstract}
Post harvest losses of fruits and vegetables could be reduced if appropriate practices after the harvest until its commercialization are adopted. For this, not only knowledge of the physiological processes of the product is necessary, but also an adequate infrastructure and distribution logistic. The indiscriminate use of chemical products for eradication of plagues and diseases in the cultivation and also in the post harvest period is being substituted successfully by methods that do not cause harm to human beings or to the environment, reasons for which physical treatments (application of heat, cold or ionized radiation) are being intensively investigated. Some parameters related to physical and physiologic quality of the guava "Pedro Sato", were determined in this research, after complete immersion of the fruits in hot water at a temperature of $47{ }^{\circ} \mathrm{C}$ during $6 \mathrm{~min}$, and stored at 8 and $22{ }^{\circ} \mathrm{C}$, with medium relative humidity equal to $89 \%$. It was observed that the hot water treatment, in a general way, promoted retardation in the mass loss and the firmness during the storage period, but did not cause a climacteric ascension in the production of $\mathrm{CO}_{2}$ and ethylene.
\end{abstract}

Key words: post-harvest, water immersion bath, ethene

\footnotetext{
${ }^{1}$ Doutoranda Faculdade de Engenharia Agrícola da UNICAMP, CEP 13080-571, Campinas, SP. Fone: (19) 3521-1075. E-mail: s057726@dac.unicamp.br

2 DEA/UFV, Viçosa, MG, CEP 36571-000. Fone: (31) 3899-1927. E-mail: scouto@mail.ufv.br; copace@ufv.br

3 Doutoranda DEA/UENF, CEP 28013-811, Campos, RJ. Fone: (22) 2726-1543. E-mail: aeods@bol.com.br

${ }^{4}$ DBA/UFV. Fone: (31) 3899-2510. E-mail: cecon@dpi.ufv.br

${ }^{5}$ Doutorando DTA/UFV. Fone: (31) 3899-1915. E-mail: danilojpsilva@yahoo.com.br
} 


\section{INTRODUÇÃO}

Frutos da goiabeira (Psidium guajava L.) se destacam dentre os frutos tropicais não só devido às suas boas características organolépticas (sabor e aroma) como também nutricionais, sendo considerados, portanto, alta fonte de vitamina C, teores de vitamina A e do grupo B, como a tiamina e a niacina, fibras e minerais como fósforo, ferro e cálcio (El Bulk et al., 1997), possuem ainda alto conteúdo de licopeno, um importante carotenóide que ajuda no combate a doenças cardiovasculares e possui características funcionais anticancerígenas (Bramley, 2002; Lerici et al., 2000; Shi et al., 1999; CEAGESP, 2006). Além dessas características benéficas a goiaba é um fruto com excelente aceitação para o consumo natural e de grande importância na indústria, em virtude do seu aproveitamento na forma de vários produtos, como goiabadas, geléias, pastas, fruta em calda, purê, alimento para criança, base para bebidas, refrescos, sucos e xaropes.

Embora ofereça várias opções de aproveitamento, a goiaba é altamente perecível e seus processos fisiológicos são bastante acelerados enquanto seus efeitos, agravados pelas condições às quais os frutos são submetidos durante e após a colheita, tornam sua comercialização limitada em face das possíveis perdas que podem ocorrer nesse período. A falta do emprego de tecnologias de conservação limita o período de comercialização e diminui a qualidade dos frutos, ocasionando redução do número de mercados consumidores (Azzolini, 2002). Durante o seu desenvolvimento e no período pós-colheita, a goiaba é atacada por diversos microrganismos e insetos, que provocam diferentes tipos de danos além desses prejuízos, as doenças e pragas trazem problemas para a exportação dos frutos, uma vez que os países maiores consumidores de frutas, aplicam rigorosas barreiras alfandegárias, exigindo tratamentos eficazes para a desinfestação dos frutos (USDA, 1997; Carvalho, 1999). As principais premissas dos importadores de frutas são a comprovação da seguridade alimentar e a adoção de boas práticas agrícolas, o que implica em uso racional e exclusivo de produtos químicos oficialmente registrados para cada cultivo, respeitando os intervalos de segurança, conservação do meio ambiente, análise de resíduos e colheita e pós-colheita (IBRAF, 2007).

Ante todas essas dificuldades, o controle por meio de tratamentos físicos, como a aplicação de calor, do frio, radiação ionizante, radiação UV-C associados ao uso de atmosferas modificadas, inibidores do amadurecimento e armazenamento refrigerado, está sendo amplamente estudado (Vicente et al., 2006; Pinheiro et al., 2005; Vieira, 2004).

Neste contexto o presente trabalho teve por objetivo avaliar parâmetros relacionados à qualidade física e fisiológica do produto tratado hidrotérmicamente a $47^{\circ} \mathrm{C}$, durante 6 minutos, binômio encontrado em testes preliminares e escolhido por não causar danos visuais (escaldaduras) nos frutos e por ser eficiente no controle de ovos e larvas de moscas-das-frutas.

\section{MATERIAL E MÉTODOS}

Este estudo foi realizado no Laboratório de Propriedades Físicas do Departamento de Engenharia Agrícola (DEA) da UFV, localizado no campus da Universidade Federal de Viçosa. Utilizaram-se frutos da goiabeira (Psidium guajava L.) do cultivar 'Pedro Sato,' provenientes do pomar comercial situado no município de Viçosa, MG. A colheita manual dos frutos foi realizada pela manhã, no estádio de maturação, correspondente à coloração verde-mate; após a colheita, os frutos foram acondicionados em contentores de plástico dispostos em duas camadas, protegidos internamente por folhas de papel e encaminhados imediatamente ao laboratório.

\section{Caracterização física inicial dos frutos}

No laboratório, procedeu-se a uma rigorosa seleção visual, com vistas à obtenção de lotes mais uniformes, eliminando-se os frutos que apresentavam qualquer dano causado durante o período do transporte. Para caracterizar o material vegetal em estudo, foram determinados: dimensões (longitudinal e diâmetro máximo), massa da matéria fresca, volume e densidade real, para dimensões, se utilizou um paquímetro digital Digimess com precisão de 0,01 mm, enquanto para determinação da massa se utilizou-se de balança eletrônica BG 4000 com precisão de 0,01 g. As determinações de volume foram feitas pelo método de complementação de volume, usando-se água como líquido complementador (Moreira et al., 1984). Os cálculos das densidades médias do produto foram feitos através da relação massa/volume $\left(\mathrm{g} \mathrm{cm}^{-3}\right)$.

\section{Tratamento hidrotérmico}

O tratamento hidrotérmico dos frutos de goiaba foi realizado em um recipiente cilíndrico com capacidade para $65 \mathrm{~L}$ de água, simulando um equipamento banho-maria, contendo isolamento térmico (lã de vidro) nas laterais e na base. O aquecimento da água no recipiente foi efetuado por uma resistência de múltiplo passe (sete voltas) controlada por um termostato previamente calibrado, do tipo "T".

Como não havia informação na literatura sobre temperatura e tempo de exposição de banho mais adequado para eliminar os ovos e larvas de mosca-da-fruta para a goiaba, se investigou inicialmente, três temperaturas de imersão dos frutos de goiaba, a 47,49 e $51^{\circ} \mathrm{C}$, que são temperaturas próximas à temperatura utilizada para tratamento térmico padrão em mamões e mangas e para aumentar a eficiência do uso de fungicida em goiabas, respectivamente.

Para cada temperatura foram realizadas três repetições, cada uma construída por um fruto; após a estabilização da temperatura da água do banho-maria procedeu-se à imersão dos frutos, individualmente, na água por meio de uma cesta. Para o acompanhamento da temperatura no interior e no exterior dos frutos, foram inseridos termopares tipo "T" (agulhas hipodérmicas) previamente calibrados e ligados a um sistema de aquisição de dados marca Minmax S210RA, acoplado a um microcomputador, onde as temperaturas eram registradas e armazenadas em intervalos de tempo regulares de $1 \mathrm{~min}$. 


\section{Pré-resfriamento}

Após o tratamento hidrotérmico, os frutos foram pré-resfriados em um tanque contendo solução $500 \mathrm{mg} \mathrm{L}^{-1}$ de fungicida da marca Sportak 450 C.E em água a $10^{\circ} \mathrm{C}$, durante 5 minutos e, em seguida, acondicionados em bandejas de isopor com capacidade para 1 fruto e recobertas com filmes de PVC com espessura igual a $15 \mu \mathrm{m}$.

\section{Armazenamento}

O produto foi separado em dois lotes, de acordo com a temperatura de armazenamento. Um dos lotes (T1) foi armazenado em câmaras mantidas a temperaturas de $8{ }^{\circ} \mathrm{C}$ e o outro, (T2) a temperatura de $22^{\circ} \mathrm{C}$, para simular o período em que o produto permanece em navio com destino aos mercados externo e interno, respectivamente. A umidade relativa no interior das câmaras (89\%) foi controlada através da utilização de bandejas contendo água e papel picado, monitorada diariamente por um higrômetro cuja leitura é fornecida em porcentagem. O produto armazenado na câmara a $22^{\circ} \mathrm{C}$ foi avaliado durante o período de 4 dias e aqueles armazenados a $8{ }^{\circ} \mathrm{C}$, a cada 4 dias, até o $16^{\circ}$ dia.

\section{Avaliação da qualidade do produto e índice de cor da casca}

As avaliações pelo índice de cor da casca foram feitas com base na utilização de uma escala de cores, apresentada na Figura 1, construída em laboratório para a cultivar utilizado, em testes preliminares, com auxílio de um cavalete, com posições distintas para as goiabas e câmera fotográfica. As fotos eram tiradas pela manhã e a evolução das cores foi escolhida por comparação entre goiabas durante sete dias, e com o auxílio de uma fita verde (ao lado das goiabas), que indicava se havia ou não diferenças de iluminação no ambiente.

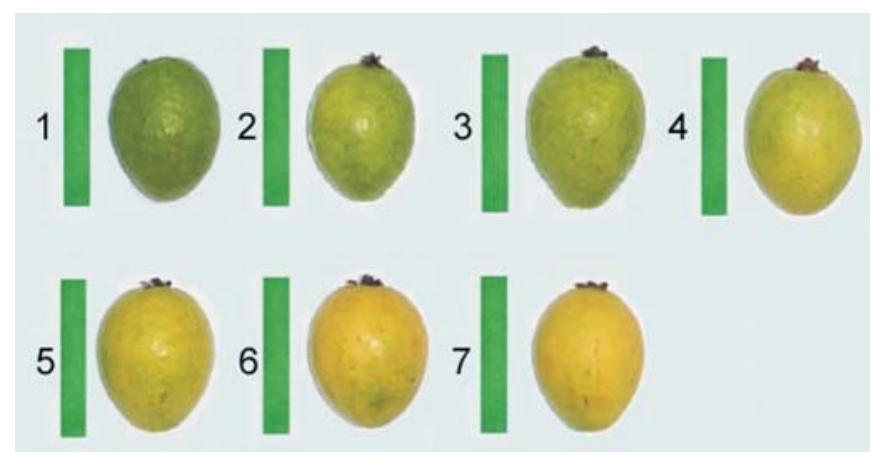

Figura 1. Valores numéricos para escala de cores para a cultivar 'Pedro Sato': 1: verde-escuro; 2: verde; 3: verde-mate; 4: verde-amarelo; 5: 50\% amarelo; 6: amarelo com base verde; 7 : totalmente amarelo

\section{Perda de massa do fruto}

A redução da massa dos frutos durante o período de armazenamento para as duas temperaturas utilizadas no experimento, foi determinada diariamente, com base na pesagem dos frutos em balança eletrônica digital (BG 4000) com precisão de $0,01 \mathrm{~g}$.

\section{Índice de firmeza dos frutos}

Definiu-se o índice de firmeza de cada um dos frutos medindo-se a força máxima necessária para introdução de uma ponteira a uma profundidade de $10 \mathrm{~mm}$ na polpa da goiaba. A ponteira padrão utilizada com diâmetro da secção transversal igual a $8 \mathrm{~mm}$ de (ASAE, 2000), foi acoplada ao cabeçote de uma máquina de ensaios, modelo EMIC.

Para determinação dessa força, o fruto foi colocado no prato horizontal da máquina, na posição de maior diâmetro com eixo longitudinal na horizontal, e após a remoção superficial da sua casca, realizaram-se os ensaios de penetração da ponteira no fruto.

Nesses ensaios, a ponteira foi acoplada ao cabeçote da máquina universal de ensaios, que trabalhou a uma velocidade de $10 \mathrm{~mm} \mathrm{~min}^{-1}$, com uma célula de carga com capacidade de $200 \mathrm{~N}$.

\section{Atividade respiratória e produção de etileno}

A atividade respiratória indicada pela quantificação da produção de $\mathrm{CO}_{2}$ e a produção de etileno, foram determinadas durante o período de armazenamento, por cromatografia gasosa. Os frutos foram colocados individualmente em frascos de vidro com capacidade de $1700 \mathrm{~mL}$ e hermeticamente fechados. Após 40 min a partir do fechamento do frasco, alíquotas de 1,0 mL de sua atmosfera foram injetadas em um cromatógrafo a gás, da marca Varian GC 3800, equipado com detectores de condutividade térmica e de ionização de chama, coluna empacotada com Hayesep R; o gás de arraste foi o nitrogênio. As temperaturas empregadas foram 80,100 e $150{ }^{\circ} \mathrm{C}$ para coluna, injetor e detector, respectivamente.

\section{Planejamento experimental}

O planejamento experimental seguiu o esquema de parcelas subdivididas tendo-se, nas parcelas, os tratamentos (frutos submetidos ou não ao tratamento hidrotérmico) e, na subparcela, os períodos de avaliação, em dias, no delineamento inteiramente casualizado com 3 repetições, cada uma constituída de cinco goiabas. Os dados foram submetidos a análise de variância e regressão; já para o fator qualitativo, testemunha padrão (T1) e tratamento térmico (T2) as médias foram comparadas utilizando-se o teste de F com nível de 5\% de probabilidade; o fator quantitativo (dias de avaliação) foi escolhido com base na significância dos coeficientes de regressão, utilizando-se o teste " $t$ " a nível de 5\% de probabilidade, no coeficiente de determinação (R2 = S.Q. Regressão/S.Q. Dias) e no potencial, para explicar o fenômeno em estudo.

\section{RESULTADOS E DISCUSSÃO}

\section{Caracterização física inicial dos frutos}

Os valores médios e respectivos desvios padrão e valores máximos e mínimos dos parâmetros utilizados na caracterização dos frutos, se encontram na Tabela 1; cada valor envolve a média de cinco frutos. 
Tabela 1.Valores médios, desvio padrão dos valores médiosevalores máximos e mínimos das grandezas avaliadas na caracterização inicial dos frutos

\begin{tabular}{lcccc}
\hline Parâmetro & \multicolumn{3}{c}{ Valor } & $\begin{array}{c}\text { Desvio } \\
\text { padrão }\end{array}$ \\
\cline { 2 - 4 } Massa $(\mathrm{g})$ & 155,86 & 172,19 & 147,72 & 9,05 \\
Volume $(\mathrm{mL})$ & 239,78 & 247,00 & 234,60 & 5,18 \\
Densidade real $\left(\mathrm{g} \mathrm{mL}^{-1}\right)$ & 0,65 & 0,73 & 0,60 & 0,04 \\
Medida longitudinal $(\mathrm{mm})$ & 96,59 & 104,70 & 87,30 & 6,23 \\
Diâmetro $(\mathrm{mm})$ & 80,23 & 83,30 & 77,40 & 1,71 \\
Firmeza da polpa $(\mathrm{N})$ & 50,00 & 55,86 & 36,65 & 5,61 \\
$\mathrm{Mg} \mathrm{CO}_{2} \mathrm{~kg}^{-1} \mathrm{~h}^{-1}$ & 41,72 & 46,00 & 34,79 & 4,67 \\
$\mu \mathrm{L} \mathrm{C} \mathrm{H}_{4} \mathrm{~kg}^{-1} \mathrm{~h}^{-1}$ & 0,04969 & 0,09707 & 0,02766 & 0,02629 \\
\hline
\end{tabular}

Avaliação da qualidade do produto submetido ao tratamento hidrotérmico e presença de escaldaduras nos frutos

A escaldadura nos frutos é caracterizada por manchas de cor marrom na casca do produto, em conseqüência da temperatura do tratamento térmico utilizado. No presente trabalho a escaldadura foi observada no sexto dia de armazenamento a $8^{\circ} \mathrm{C}$, somente nos frutos $\mathrm{T} 2$ que foram avaliados diariamente para a investigação de perda de massa e índice de cor da casca. É provável que a exposição desses frutos todos os dias, em ambientes com temperaturas e umidades relativas diferentes, possa ter causado a escaldadura.

\section{Índice de cor da casca}
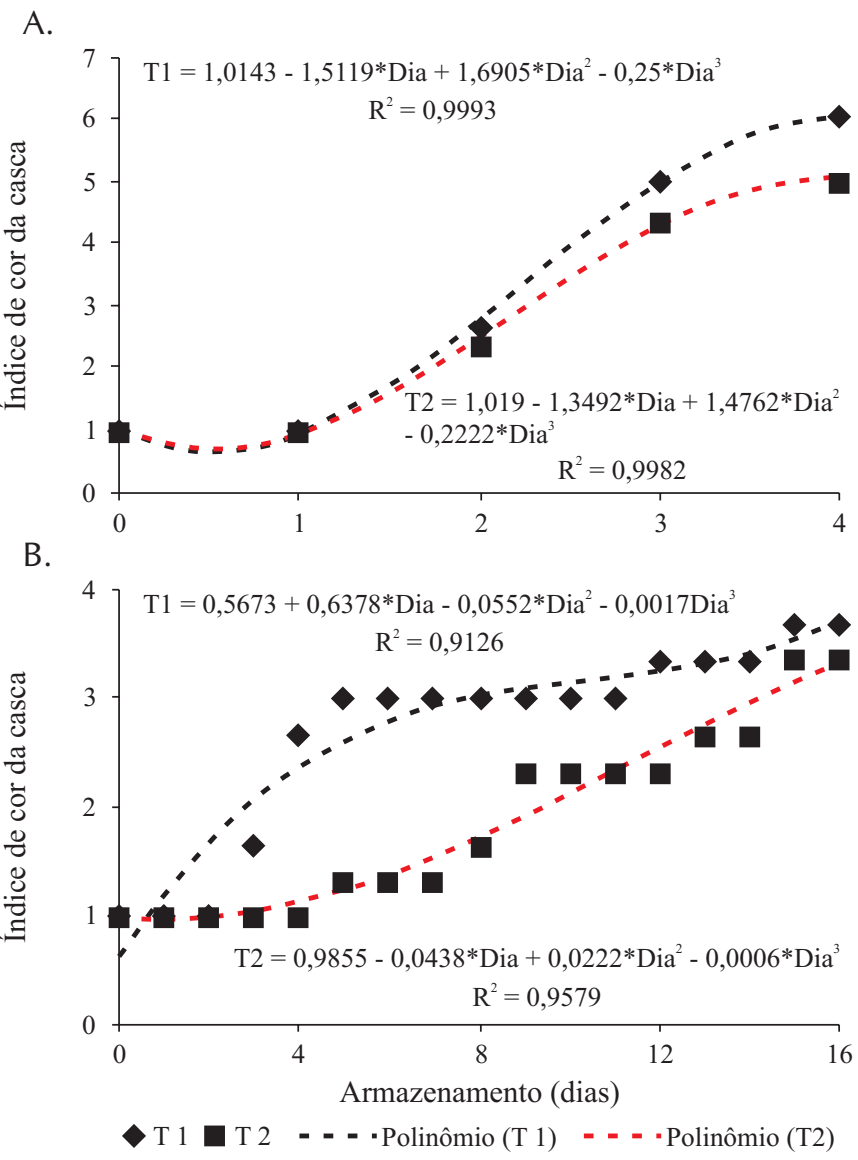

Figura 2. Índice de cor da casca dos frutos T1 e T2, armazenados a uma temperatura de $22{ }^{\circ} \mathrm{C}$ durante 4 dias $(\mathrm{A})$, e a uma temperatura de $8{ }^{\circ} \mathrm{C}$ durante 16 dias (B)
Ao final do período de armazenamento, a uma temperatura de $22{ }^{\circ} \mathrm{C}$, os frutos atingiram os índices de cor de 6 e 5 (Figura 1) para os tratamentos $\mathrm{T} 1$ e $\mathrm{T} 2$, respectivamente; os frutos do T1 apresentaram aumento mais acentuado na evolução da cor durante o período de armazenamento, enquanto os frutos T2 tiveram amarelecimento gradual e menor que os frutos testemunha, resultado que demonstra que o tratamento hidrotérmico retardou o amarelecimento dos frutos armazenados a uma temperatura de $22{ }^{\circ} \mathrm{C}$ pelo tempo de 4 dias (Figura 2A). Para os frutos armazenados a $8{ }^{\circ} \mathrm{C}$, observou-se que o tratamento T2 dos frutos também exerceu efeito sobre o índice de cor da casca do produto, retardando o seu amarelecimento. Ao final do armazenamento, os índices de cor da casca para os frutos T1 e T2 foram, respectivamente, 4 e 3,36; conforme a Figura 2B.

Ao final do período de armazenamento, notou-se que os frutos armazenados a $8{ }^{\circ} \mathrm{C}$, por 16 dias, apresentaram um índice de cor menor que os frutos armazenados a $22^{\circ} \mathrm{C}$ durante 4 dias; este comportamento indica que o tratamento hidrotérmico, associado à temperatura de armazenamento de $8{ }^{\circ} \mathrm{C}$, promove o retardamento do amarelecimento dos frutos, resultado favorável sob o ponto de vista comercial.

\section{Perda de massa do fruto}

Os resultados da perda de matéria fresca dos frutos submetidos aos diferentes tratamentos estão mostrados na Figura 3.

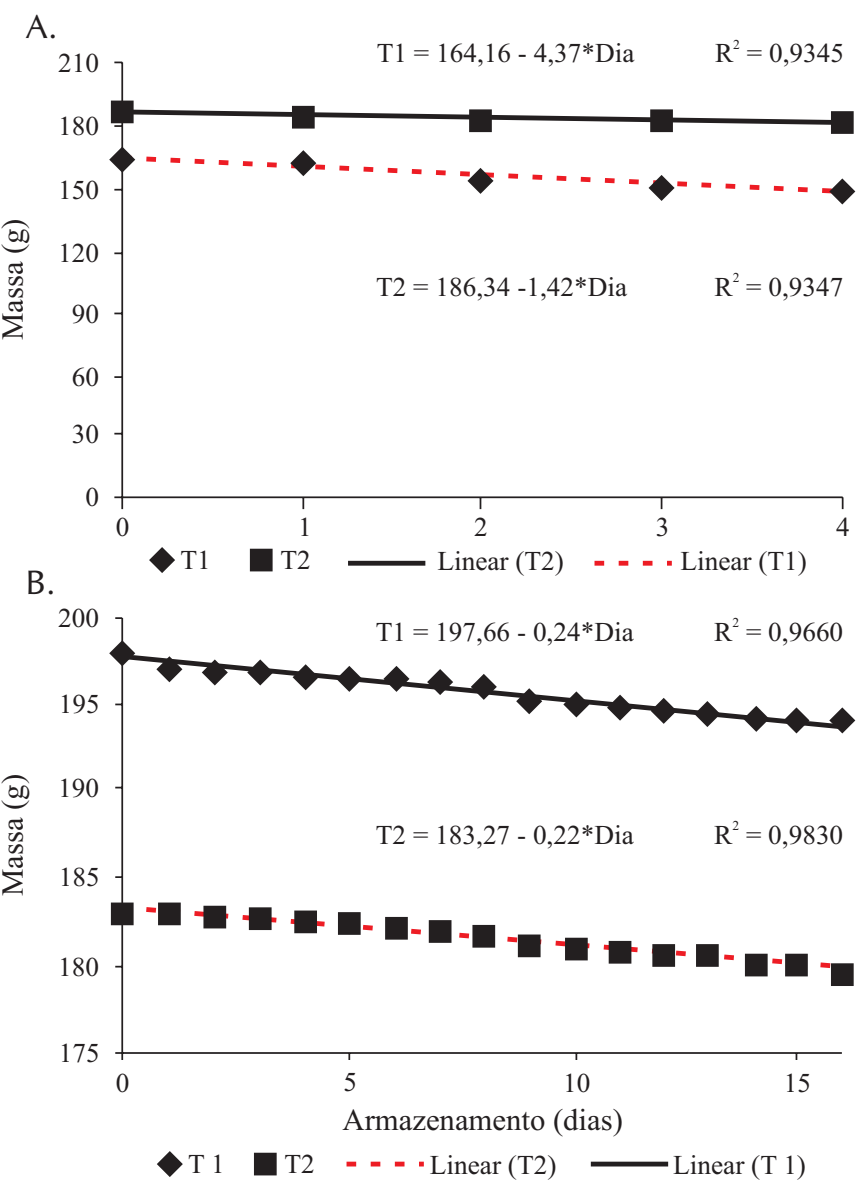

Figura 3. Massa dos frutos $\mathrm{T} 1 \mathrm{e} \mathrm{T} 2$, armazenados a uma temperatura de $22{ }^{\circ} \mathrm{C}$, durante 4 dias (A), e a uma temperatura de $8{ }^{\circ} \mathrm{C}$, durante 16 dias (B) 
Não ocorreu diferença significativa entre os tratamentos aplicados para os frutos armazenados a uma temperatura de $22{ }^{\circ} \mathrm{C}$ durante 4 dias, indicando que o tratamento hidrotérmico utilizado não promoveu perda de massa dos frutos, mas houve diferença entre os dias de armazenamento (Figura 3A).

Para os frutos armazenados a $8{ }^{\circ} \mathrm{C}$ durante 16 dias, constatou-se o mesmo comportamento ocorrido anteriormente, embora não tenha se constatatado diferença significativa entre tratamentos; no entanto, ocorreu diferença significativa entre os dias de armazenamento para cada tratamento, fato observado na Figura 3B.

Estatisticamente, não houve diferença significativa entre os tratamentos, mas apenas em relação ao tempo de armazenamento; observou-se, porém, que frutos submetidos ao tratamento testemunha apresentam tendência de maior perda de massa e amarelecimento da casca mais rápido, durante os dias de armazenamento.

\section{Firmeza dos frutos}

Não ocorreu diferença significativa entre os tratamentos aplicados para os frutos armazenados a $22{ }^{\circ} \mathrm{C}$, verificandose o oposto para cada tratamento nos dias de avaliação. As equações de regressão para os tratamentos 1 e 2 se acham na Figura 4.

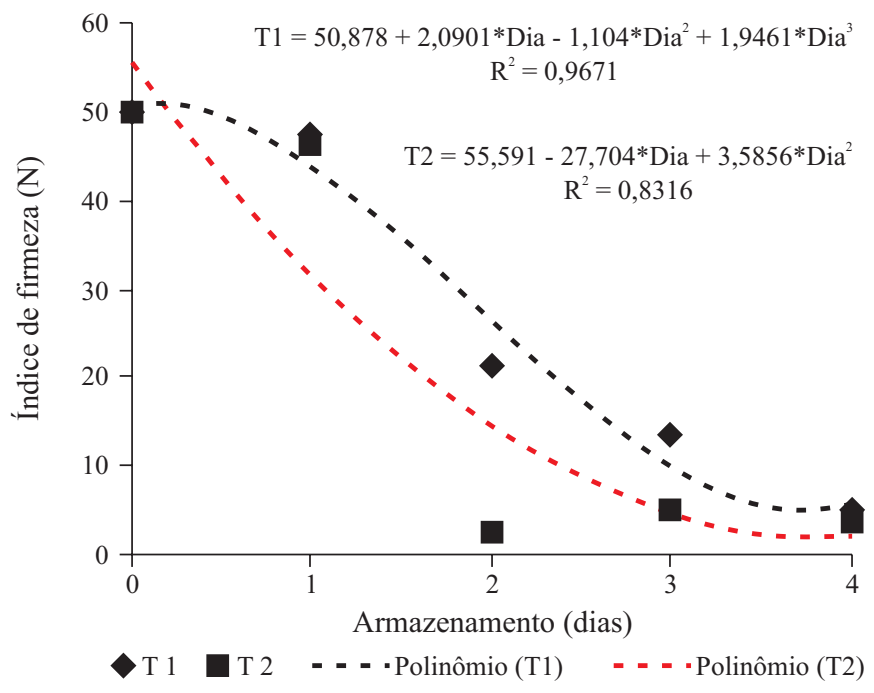

Figura 4. Firmeza da polpa dos frutos tratados T2 e T1, armazenados a uma temperatura de $22^{\circ} \mathrm{C}$ durante 4 dias

A firmeza dos frutos decresceu ao longo do armazenamento do produto. As frutas foram colhidas com firmeza média da polpa de 50,0 $\mathrm{N}$ e, após o período de armazenamento a $22{ }^{\circ} \mathrm{C}$ durante 4 dias, os valores médios para os tratamentos 1 e 2 se encontravam a 5,24 e 3,84 N, respectivamente, como mostrado na Figura 4. Sousa et al. (2002), notaram característica semelhante em mangas 'Tommy Atkins', embaladas em filmes plásticos e armazenadas em ambientes refrigerados.

Apesar de não haver diferença significativa entre os tratamentos aplicados, observa-se, no T2, que ocorreu perda brusca na firmeza da polpa da goiaba no início do armazenamento, fato que pode ser atribuído ao aumento de tempe- ratura dos frutos após o tratamento associado à temperatura de $22{ }^{\circ} \mathrm{C}$ durante o armazenamento.

Para os frutos armazenados a $8^{\circ} \mathrm{C}$, os valores médios para os frutos testemunha e tratados termicamente no final do período de armazenamento, se encontravam a 1,75 e 2,33 N, respectivamente, conforme a Figura 5.

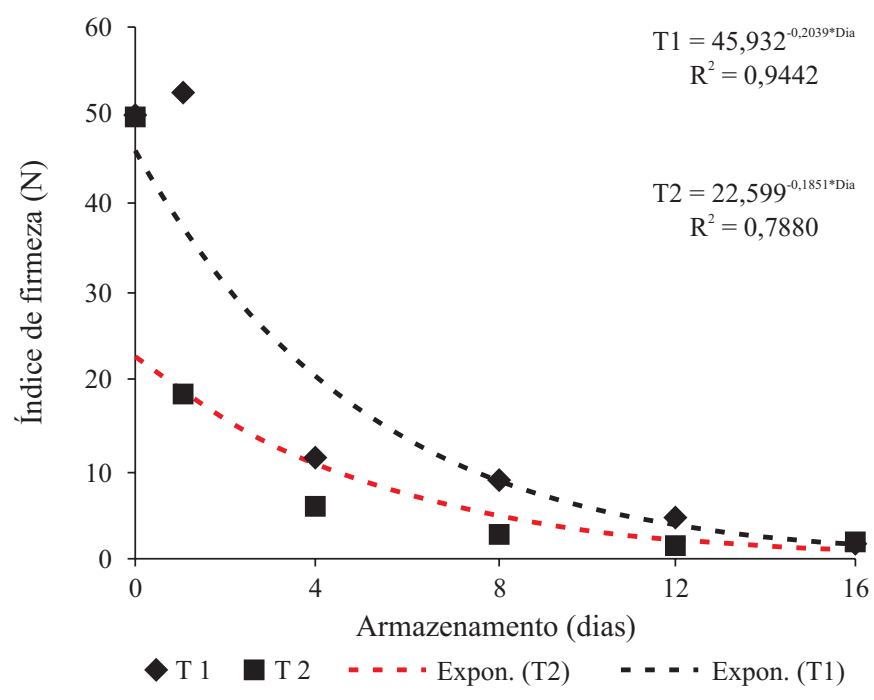

Figura 5. Perda de firmeza da polpa dos frutos $\mathrm{T} 1$ e $\mathrm{T} 2$, armazenados a temperatura de $8{ }^{\circ} \mathrm{C}$, durante 16 dias

Observou-se, durante o período de armazenamento, que os frutos submetidos ao T2, sofreram maior perda de firmeza que os frutos do T1 (Figura 5), podendo-se afirmar que o tratamento hidrotérmico exerceu influência negativa sobre a firmeza da polpa dos frutos, ao contrário do observado no estudo realizado por de Chan Jr. et al. (1981), no qual se notou redução no amolecimento em frutos de mamão, ocasionando o desenvolvimento de uma porção interna de tecido endurecido.

\section{Atividade respiratória e produção de etileno $\left(\mathrm{C}_{2} \mathrm{H}_{4}\right)$}

Não houve diferença significativa entre os tratamentos em relação à produção de $\mathrm{CO}_{2}$ e produção de etileno, para os frutos armazenados a temperatura de $22^{\circ} \mathrm{C}$, mas esta diferença significativa foi notória entre os dias de armazenamento para cada tratamento. Os valores médios de produção de $\mathrm{CO}_{2}$ e $\mathrm{C}_{2} \mathrm{H}_{4}$ em função dos dias de armazenamento, podem ser representados pelas equações das Figura 6A e B, respectivamente.

Para os frutos submetidos ao T1 verificou-se aumento acentuado da atividade respiratória com posterior diminuição; isto ocorre com frutos que apresentam o padrão climatérico de respiração, segundo Castro (2003); após a colheita do fruto, há um aumento gradual da taxa respiratória até atingir seu nível mais alto ou máximo climatérico; o mesmo não se deu com os frutos submetidos ao T2, visto que não se observou diminuição da atividade respiratória durante o período de armazenamento, comportamento este que indica que a atividade respiratória foi retardada pelo tratamento hidrotérmico, comportamento semelhante verificado por Paull \& Chen (1989), ao afirmarem que o tratamento térmico afeta a taxa respiratória. 
A.
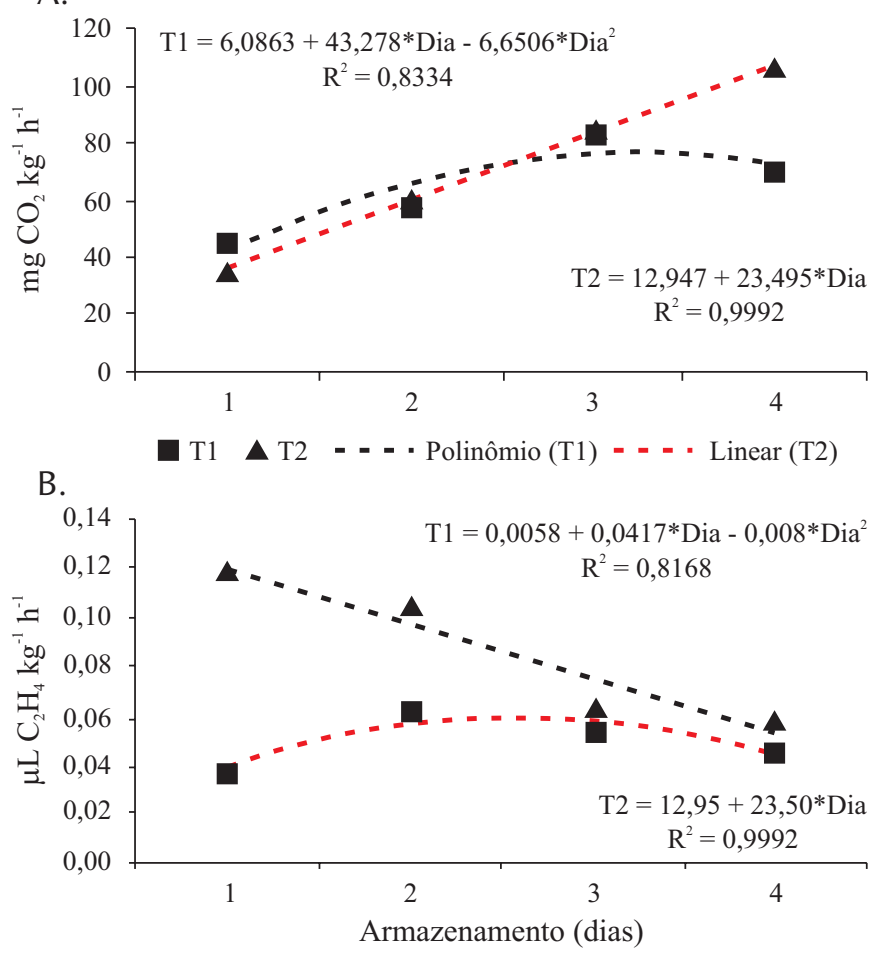

T1 $\mathbf{\Delta}$ T2 = - - Polinômio (T1) - - - - Linear (T2)

Figura 6. (A) Taxa de produção de $\mathrm{CO}_{2}$ dos frutos $\mathrm{T} 1$ e $\mathrm{T} 2$, armazenados a temperatura de $22^{\circ} \mathrm{C}$, durante 4 dias; (B) Concentrações de $\mathrm{C}_{2} \mathrm{H}_{4}$ dos $\mathrm{T} 1$ e T2, armazenados a uma temperatura de $22^{\circ} \mathrm{C}$, durante 4 dias

Em relação à produção de $\mathrm{C}_{2} \mathrm{H}_{4}$ para os frutos do tratamento $\mathrm{T} 1$, armazenados a uma temperatura de $22{ }^{\circ} \mathrm{C}$, verifica-se comportamento semelhante ao da atividade respiratória, com aumento gradual até o terceiro dia, seguido de uma posterior diminuição, confirmando a ocorrência do pico climatérico, observado na Figura 6B.

Para os frutos submetidos ao tratamento T2, constatou-se declínio gradual na produção de $\mathrm{C}_{2} \mathrm{H}_{4}$ até o fim do período de armazenamento. $\mathrm{O}$ declínio na produção de $\mathrm{C}_{2} \mathrm{H}_{4}$ pode ser entendido como resposta ao tratamento hidrotérmico. Em relação ao armazenamento a temperatura de $8{ }^{\circ} \mathrm{C}$, não se verificou diferença significativa entre tratamentos, tanto para as avaliações de produção de $\mathrm{CO}_{2}$ quanto para a produção de etileno no entanto, houve diferença significativa entre os dias de armazenamento para cada tratamento. As concentrações de $\mathrm{CO}_{2}$ e $\mathrm{C}_{2} \mathrm{H}_{4}$ produzidas pelos frutos durante os dias de armazenamento a $8{ }^{\circ} \mathrm{C}$, se encontram nas Figura 7A e B, respectivamente.

Para os frutos armazenados a temperatura de $8{ }^{\circ} \mathrm{C}$ se constatou, o máximo climatérico nos frutos submetidos ao T1 no quarto dia de armazenamento, um dia após o notado nos frutos armazenados a $22^{\circ} \mathrm{C}$ submetidos ao mesmo tratamento. Para os frutos submetidos ao T2, não se verificou o máximo climatérico, indicando que o tratamento hidrotérmico suprimiu a taxa respiratória dos frutos armazenados a uma temperatura de $8{ }^{\circ} \mathrm{C}$.

A produção de $\mathrm{C}_{2} \mathrm{H}_{4}$ para o tratamento $\mathrm{T} 1$ sofreu aumento gradual e se observou máximo climatérico no décimo segundo dia de armazenamento a $8{ }^{\circ} \mathrm{C}$. O mesmo não ocorreu
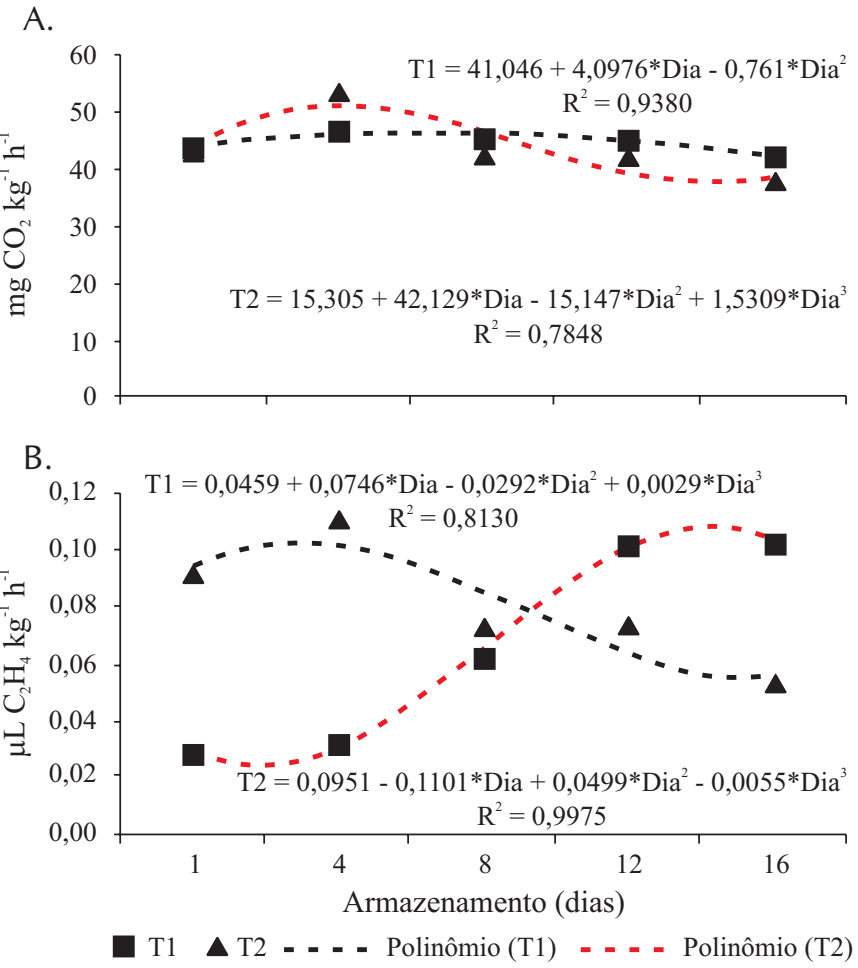

Figura 7. (A) Taxa de produção de $\mathrm{CO}_{2}$ dos frutos $\mathrm{T} 1$ e $\mathrm{T} 2$, armazenados a temperatura de $8{ }^{\circ} \mathrm{C}$, durante 16 dias; (B) Concentrações de $\mathrm{C}_{2} \mathrm{H}_{4}$ dos frutos T1 e T2, armazenados a uma temperatura de $8{ }^{\circ} \mathrm{C}$ durante 16 dias

para os frutos submetidos ao tratamento hidrotérmico, nos quais se deu uma queda na produção de etileno, observada até o final do período de armazenamento.

\section{CONCLUSÕES}

Nas condições em que o experimento foi realizado, concluiu-se que o tratamento hidrotérmico a $47^{\circ} \mathrm{C}$ durante 6 min, não influenciou no amarelecimento dos frutos, na perda de massa e firmeza, não se observou ascensão climatérica na produção de $\mathrm{CO}_{2}$ e etileno $\left(\mathrm{C}_{2} \mathrm{H}_{4}\right)$ nas duas temperaturas de armazenamento avaliadas.

\section{LITERATURA CITADA}

ASAE American Society of Agricultural Engineers. Agricultural engineers yearbook of standards. St. Joseph: ASAE, 2000.

Azzolini, M. Fisiologia pós-colheita de goiabas 'Pedro Sato' estádios de maturação e padrão respiratório. Piracicaba, ESALQ/USP, 2002. 100p. Dissertação Mestrado

Bramley, P. M. Is licopene beneficial to human health? Phytochemistry, v.54. p.233-236, 2002.

Carvalho, H. A. de. Utilização da atmosfera modificada na conservação pós-colheita da goiaba 'Kumagai'. Lavras: Universidade Federal de Lavras, 1999. 155p. Tese Doutorado

Castro, P. R. C. Hormônios vegetais. http://www.ciagri.usp.br/ 'lazaropp/FisioVegGrad/Hormonios.html, 18 Out 2003. 
CEAGESP - Companhia de Entrepostos e Armazéns Gerais de São Paulo. A goiaba em números. http://www.ceagesp.gov.br, 15 mar. 2006.

Chan Jr., H. T.; Tam, S. Y. T.; Seo, S. T. Papaya polygalacturonase and is role in thermally injured ripening fruit. Journal of Food Science, v.46, p.190-197, 1981.

El-Bulk, R. E.; El-Babiker, F. E.; El-Tinai, A. H. Changes in chemical composition of fruits during development and ripening. Food Chemistry, v.59, n.3, p.395-399, 1997.

IBRAF- Instituto Brasileiro de Frutas. Revista Frutas e Derivados. p.19-26. Ano 2, ed.5, 2007.

Lerici, C. R.; Nicoli, M. C.; Anese, M. The weight given to food processing at the Food and Câncer Prevention III Symposium, Italian Journal of Food Science, 2000, v.12, n.1, p.3-7.

Moreira, S. M. C.; Chaves, M. A.; Oliveira, L. M. Comparação da eficiência de líquidos na determinação da massa específica aparente de grãos agrícolas. Revista Brasileira de Armazenamento, v.9, n.1/2, p.22-24, 1984.

Paull, R. E.; Chen, N. J. Waxing and plastic wraps influence water loss from papaya fruit during storage and ripening. Journal American Society HortScience, v.114, p.937-942, 1989.
Pinheiro, A. C. M.; Vilas Boas, E. V. de B.; Mesquita, C. T. Ação do 1-metilciclopropeno (1-MCP) na vida-de-prateleira da banana 'Maçã'. Revista Brasileira de Fruticultura, v.27, n.1, p.25-28, 2005.

Shi, J.; Le Maguer, M.; Kakuda, Y.; Lipta, Y. A.; Niekamp, F. Licopene degradation and isomeration in tomato dehydration. Food Research International, v.32. p.15-21, 1999.

Sousa, J. P. de; Praça, E. F.; Alves, R. E.; Neto, F. B.; Dantas, F. F. Influência do armazenamento refrigerado em associação com atmosfera modificada por filmes plásticos na qualidade de mangas 'Tommy Atkins'. Revista Brasileira de Fruticultura, v.24, n.3, p.665-668, 2002.

USDA-APHIS-PPQ. Pest risk assessments: Hawaiian fruits. Riverdale: U.S. Department of Agriculture, Animal Plant Health Inspection Service, Plant Protection Quarantine, 1997.

Vicente, A. R.; Martínez, G. A.; Chaves, A. R.; Civello, P. M. Effect of heat treatment on strawberry fruit damage and oxidative metabolism during storage. Postharvest Biology and Techcnology, n.40, p.116-122, 2006.

Vieira, S. M. J. Qualidade pós-colheita de goiaba submetida ao tratamento hidrotérmico. Viçosa: DEA/UFV. 39p. 2004. Dissertação Mestrado 